\title{
Status hidrasi, tingkat kebugaran jasmani dan daya konsentrasi anak sekolah dasar
}

\author{
Agus Sudrajat $^{1 *}$, Maria Mexitalia ${ }^{2}$, Ali Rosidi ${ }^{3}$
}

\section{ABSTRACT}

Background: The dehydration correlated with physical fitness and the cognition. The cardiorespiratory fitness correlated with brain ability and working performance too.

Objectives: The purpose of this study is to assess the correlation of dehydration status and cardiorespiratory fitness with the concentration of primary school children.

Methods: Correlational study is done to the students aged 10-12 years old. The dehydration status is measured by urine specific gravity. The cardiorespiratory fitness is measured by harvard step test and digit symbol test is used to measure concentration. The analysis of the data using product moment to bivariate analysis and partial correlation to multivariate analysis.

Results: The result showed that the average of subjects have a mild (Usg $1020.20 \pm 6.99 \mathrm{~g} / \mathrm{dl}$ ). The average of the subjects have a less cardiorespiratory fitness $(31.27 \pm 8.00)$. The results of concentration ability measurement showed about of $35 \pm 12.27$. The correlation analysis showed a significant correlation between dehydration status with cardiorespiratory fitness $(r=-0.29, p=0.04$ ), between dehydration status with concentration $(r=-0.29, p=0.036)$ and between cardiorespiratory fitness with concentration $(r=0.295, p=0.03)$. Partial correlation analysis showed the persistence of a significant correlation between dehydration status and cardiorespiratory fitness $(p=0.02)$, between dehydration status and concentration $(p=0.02)$ and between cardiorespiratory fitness and concentration ( $p=0.002)$.

Conclusion: There is a significant correlation between dehydration status and cardiorespiratory fitness. There is a significant correlation between dehydration status and the concentration. There is a significant correlation between cardiorespiratory fitness and the concentration.

Keywords: dehydration status; urine specific gravity; cognition; concentration; cardiorespiratory fitness

\begin{abstract}
ABSTRAK
Latar belakang: Dehidrasi dihubungkan dengan melemahnya fungsi kognisi. Selain itu daya tahan jantung paru juga dihubungkan dengan kemampuan fungsi otak dan performa kerja.

Tujuan: Tujuan penelitian ini adalah mengkaji hubungan status hidrasi dan tingkat kebugaran jasmani dengan daya konsentrasi anak sekolah dasar.

Metode: Penelitian korelasional dilakukan pada 50 anak sekolah berusia 10-12 tahun. Status hidrasi diukur dengan berat jenis urin. Harvard step test dilakukan untuk mengukur tingkat kebugaran jasmani dan tes digit simbol digunakan untuk mengukur daya konsentrasi. Analisis data menggunakan uji korelasi pearson.

Hasil: Hasil penelitian menunjukkan rata-rata subyek mengalami dehidrasi ringan (Berat jenis urin 1020,20 $\pm 6,99 \mathrm{~g} / \mathrm{dl}$ ). Rerata subyek memiliki tingkat kebugaran jasmani yang kurang $(31,27 \pm 8,00)$. Hasil pengukuran daya konsentrasi menunjukkan rerata sebesar $35 \pm 12,27$. Analisis hubungan memperlihatkan adanya hubungan bermakna $(r=-0,29, p=0,03)$ antara status dehidrasi dengan daya konsentrasi. Terdapat hubungan bermakna antara ketahanan kardiorespirasi dengan daya konsentrasi $(r=0,29$, $p=0,03$ ).
\end{abstract}

Simpulan: Ada hubungan bermakna antara status hidrasi dengan daya konsentrasi. Ada hubungan bermakna antara tingkat kebugaran jasmani dengan daya konsentrasi.

Kata kunci : status hidrasi; berat jenis urin; kognisi; daya konsentrasi; kebugaran jasmani

\section{PENDAHULUAN}

Air sebagai komponen utama pada tubuh manusia menyumbang sebanyak $60 \%-70 \%$ berat badan total dan memiliki peran yang sangat penting. ${ }^{1}$ Dalam otak mengandung $85 \%$ air, dan perubahan kecil keseimbangan cairan dapat menyebabkan gangguan kinerja otak. Perubahan osmolalitas cairan pusat sistem syaraf menyebabkan penurunan bahan bakar neuron, yang kemudian menyebabkan terjadinya hiperpolarisasi membran. Terjadinya hiperpolarisasi menyebabkan kesulitan mencapai fungsi kognisi berupa perhatian (attention) yang baik. ${ }^{2}$

Penelitian menunjukkan adanya hubungan antara dehidrasi dengan berkurangnya kemampuan kognisi

\footnotetext{
${ }^{1}$ Program Studi Pendidikan Guru Pendidikan Anak Usia Dini, Fakultas Ilmu Pendidikan, Universitas Ivet. J1. Pawiyatan Luhur IV No. 17, Bendan Dhuwur, Gajah Mungkur, Kota Semarang, Jawa Tengah 50233.

${ }^{2}$ Departemen Ilmu Kesehatan Anak, Fakultas Kedokteran, Universitas Diponegoro. Jl. Prof. Sudarto SH, Tembalang, Semarang, Jawa Tengah 50275.

${ }^{3}$ Program Studi Gizi, Fakultas Ilmu Keperawatan dan Kesehatan, Universitas Muhammadiyah Semarang. Jl. Kedung Mundu Raya No.18, Kedungmundu, Kec. Tembalang, Kota Semarang, Jawa Tengah 50273.

${ }^{*}$ Korespondensi : E-mail: nuunqalam41@gmail.com
} 
dalam tes perhatian, memori, dan fungsi psikomotor. ${ }^{3}$ Dehidrasi tingkat ringan hingga sedang dihubungkan dengan melemahnya fungsi kognisi seperti memori jangka pendek, perbedaan persepsi, kemampuan aritmatika, pekerjaan visuomotor, dan kemampuan psikomotor. ${ }^{4}$ Hasil penelitian pada anak sekolah dasar di Zambia tidak ditemukan adanya hubungan antara status hidrasi dengan perhatian, namun beberapa bukti menunjukkan bahwa murid yang terhidrasi $(\mathrm{BJU}<1,020)$ dan murid yang memiliki status hidrasi baik memiliki kemampuan lebih baik pada tes perhatian visual. ${ }^{5}$

Penelitian pada anak sekolah dasar daerah perkotaan di Indonesia menunjukkan asupan air putih masih jauh dari kecukupan, terdapat 70,9 \% pada anak laki-laki dan 49,0\% pada anak perempuan asupannya di bawah $2000 \mathrm{~mL}$. Hasil pemeriksaan tanda dehidrasi menunjukkan sebanyak 67,4\% anak laki-laki dan 62,8 $\%$ anak perempuan menunjukkan kemungkinan mengalami dehidrasi ringan dengan mengalami minimal tiga dari tanda-tanda fisik dehidrasi. ${ }^{6}$

Kebugaran jasmani merupakan kemampuan tubuh untuk melakukan aktivitas sehari-hari tanpa menimbulkan kelelahan yang berarti. Daya tahan kardiorespirasi merupakan salah satu komponen kebugaran jasmani. Daya tahan kardiorespirasi dihubungan dengan kemampuan otak dalam menyelesaikan masalah untuk meningkatkan performa kerja. ${ }^{7}$ Berdasarkan latar belakang tersebut peneliti tertarik untuk melakukan penelitian tentang hubungan antara status hidrasi dan tingkat kebugaran jasmani dengan daya konsentrasi anak sekolah dasar. Penelitian ini bertujuan mengkaji hubungan status hidrasi dan tingkat kebugaran jasmani dengan daya konsentrasi pada anak sekolah dasar.

\section{BAHAN DAN METODE}

Desain penelitian yang dilakukan adalah korelasional. Subjek penelitian ini adalah anak sekolah dasar berusia 10-12 tahun. Pemilihan subyek dilakukan dengan metode multistage random sampling, dengan kriteria inklusi yaitu tidak dalam keadaan sakit berat dan tidak mengalami gangguan fisik serta psikologis yang berat, bersedia berpartisipasi dalam penelitian dengan menyerahkan informed consent yang ditanda tangani oleh orang tua subyek. Berdasarkan pengambilan sampel didapatkan 50 siswa SD yang memenuhi kriteria inklusi, terdiri dari 21 siswa laki-laki dan 29 siswa perempuan. Rerata umur subyek $10,18 \pm 0,44$ tahun, dengan rentang $10-12$ tahun

Status hidrasi ditentukan dengan mengukur berat jenis urin yang dilakukan di laboratorium dengan kategori well-hydrated apabila nilai $\mathrm{BJU}<1,020 \mathrm{~g} / \mathrm{dl}$, minimal dehydration apabila nilai BJU 1,020-1,024 g/dl, significant dehydration apabila nilai BJU 1,025-1,029 $\mathrm{g} / \mathrm{dl}$, dan seriously dehydration apabila nilai $\mathrm{BJU} \geq 1,030$ $\mathrm{g} / \mathrm{dl} .^{8}$

Tingkat kebugaran jasmani diukur dengan menggunakan Harvard step test yang telah dimodifikasi menggunanakan bangku setinggi 12 inci atau $30,48 \mathrm{~cm}$, hingga waktu maksimal 3 menit dengan tempo 24 kali per menit. Denyut nadi dihitung pada menit ke 1 menit 30 detik setelah tes, 2 menit 30 detik setelah tes, dan 3 menit 30 detik setelah tes, masing-masing selama 30 detik. ${ }^{9}$

Daya konsentrasi diukur dengan penilaian tes digit simbol. Tes ini dilakukan selama 90 detik dengan menggambar simbol pada kotak dibawah angka sesuai kunci simbol dan angka yang ada seperti pada gambar 1 . Hasil penilaian dapat dilihat dari jumlah jawaban benar, jika benar mendapat nilai 1 dan salah mendapat nilai 0 .

Data yang terkumpul dilakukan cleaning, coding, tabulasi dan dimasukan ke dalam komputer. Normalitas sebaran data dilakukan uji Kolmogorof Smirnov. Data berskala ratio disajikan sebagai rerata dan simpang baku. Uji korelasi pearson digunakan untuk mengetahui hubungan antar variabel. Penelitian dilakukan setelah mendapatkan persetujuan komisi etik No. 571/EC/FKRSDK/2016.

Digit symbol substitution test

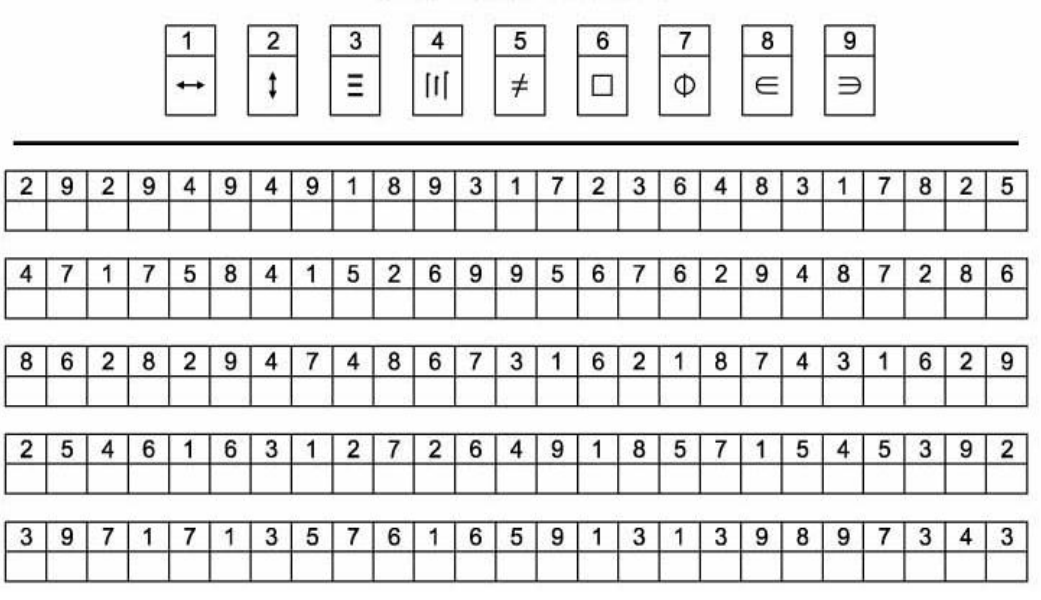

Gambar 1. Tes digit simbol 
Tabel 1. Rerata dan Standar Deviasi Data Penelitian

\begin{tabular}{lll}
\hline Variabel & Rerata & SD \\
\hline Status hidrasi(g/dl) & $1020,2 \pm 6,99$ & $1010-1030$ \\
Tingkat kebugaran jasmani & $31,27 \pm 8$ & $19,03-57,42$ \\
Daya konsentrasi & $35,0 \pm 12,27$ & $4-60$ \\
\hline
\end{tabular}

Tabel.2. Hubungan Setatus Hidrasi, Tingkat Kebugaran Jasmani dan Daya Konsentrasi

\begin{tabular}{lcc}
\hline Parameter & r & p \\
\hline Status hidrasi dan daya konsentrasi & $-0,29$ & 0,03 \\
Tingkat kebugaran jasmani dan daya konsentrasi & 0,29 & 0,03 \\
\hline
\end{tabular}

kebugaran jasmani dan daya konsentrasi

Uji korelasi pearson. *signifikan $\mathrm{p}<0,05$

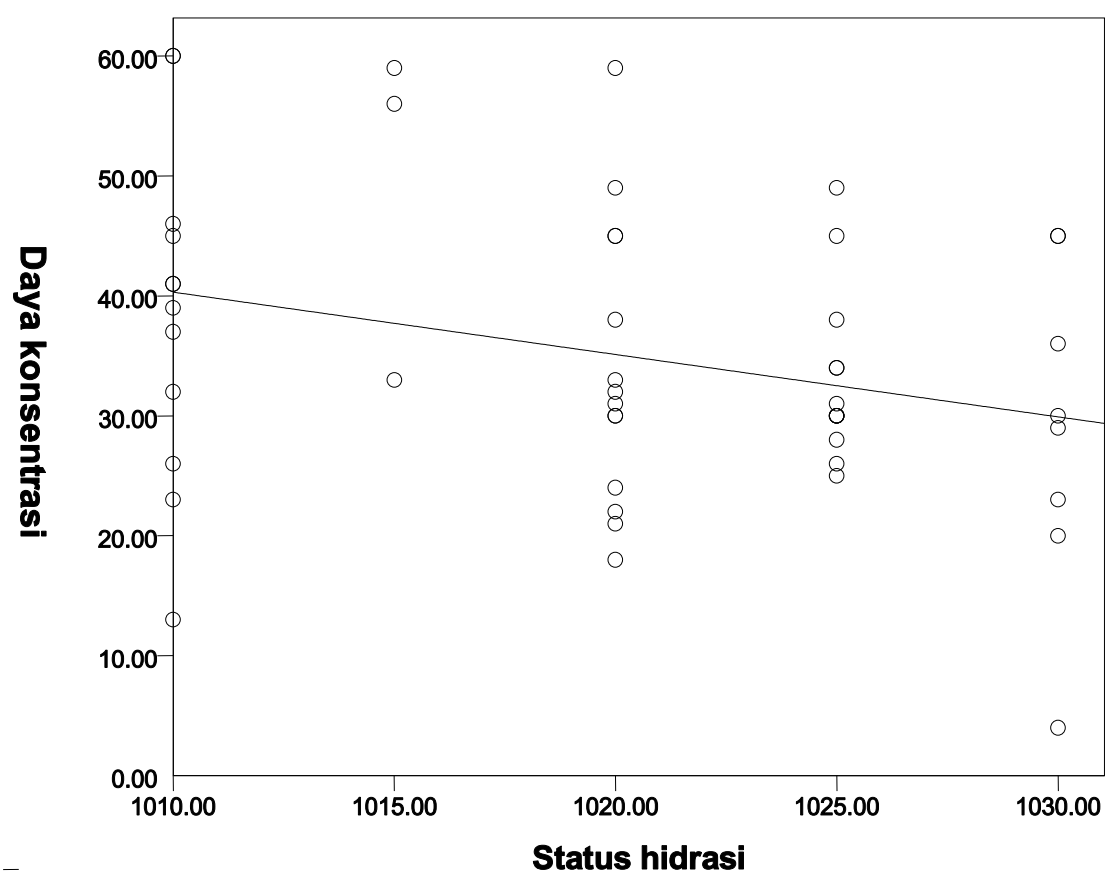

Gambar 2. Hubungan Status Hidrasi dengan Daya Konsentrasi

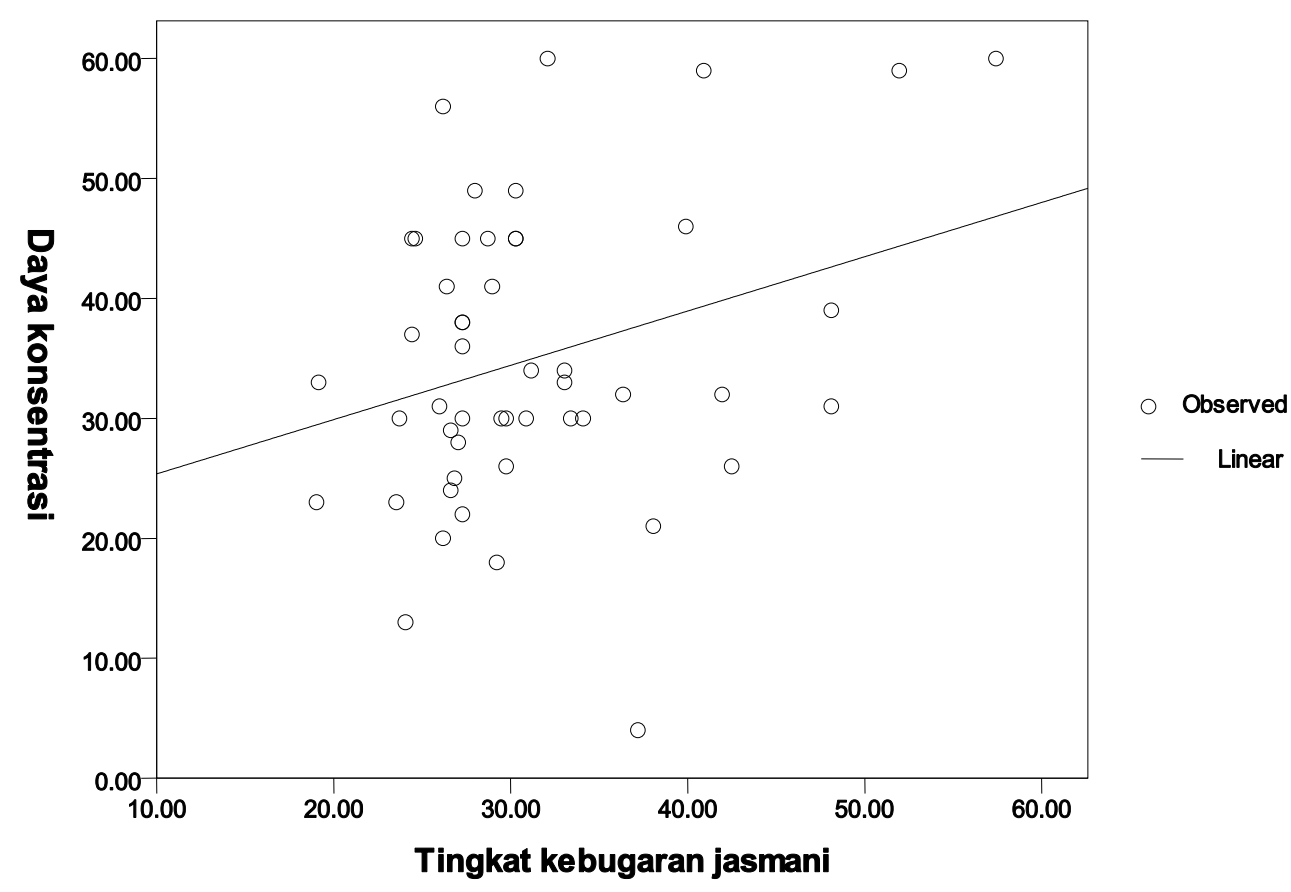

Gambar 3. Hubungan Tingkat Kebugaran Jasmani dengan Daya Konsentrasi 


\section{HASIL}

Hasil pengukuran status hidrasi subyek pada tabel 1 menunjukkan rerata mengalami dehidrasi ringan (BJU $1020,20 \pm 6,99 \mathrm{~g} / \mathrm{dl}$ ). Hasil pengukuran tingkat kebugaran jasmani menunjukkan rerata subyek memiliki tingkat kebugaran jasmani yang kurang $(31,27 \pm 8,00)(<50)$. Hasil pengukuran daya konsentrasi dengan digit symbol test menunjukkan rerata nilai digit symbol subyek sebesar $35 \pm 12,27$.

Gambar 2 menunjukkan arah negatif antara status hidrasi dengan daya konsentrasi yang berarti semakin dehidrasi semakin rendah nilai daya konsentrasinya. Analisis korelasi memperlihatkan hubungan yang bermakna $(p<0,05)$ dengan kekuatan hubungan $\mathrm{r}=-0,29$.

Gambar 3 memperlihatkan arah positif antara tingkat kebugaran jasmani dengan daya konsentrasi yang berarti semakin tinggi nilai tingkat kebugaran jasmani semakin tinggi nilai daya konsentrasinya. Analisis korelasi memperlihatkan hubungan yang bermakna $(p<0,05)$ dengan kekuatan hubungan $r=0,29$.

\section{PEMBAHASAN}

Hasil analisis menunjukkan adanya hubungan yang bermakna $(p<0,05)$ antara status hidrasi dengan daya konsentrasi. Arah hubungan negatif dikarenakan semakin dehidrasi, semakin rendah daya konsentrasinya. Hasil penelitian ini berbeda dengan penelitian pada anak sekolah dasar di Zambia yang tidak menemukan adanya hubungan yang bermakna antara status hidrasi dengan perhatian, namun beberapa bukti menunjukkan bahwa murid yang diklasifikasikan sebagai terhidrasi $(B J U<1,020)$ dan murid yang memiliki status hidrasi lebih baik memiliki kemampuan lebih baik pada tes perhatian visual. ${ }^{5}$

Studi pada anak sekolah (6-12 tahun) dalam keadaan dehidrasi yang disebabkan kurangnya asupan air tanpa melihat pengaruh kondisi lingkungan, menunjukkan hasil subyek yang tidak minum air memiliki nilai tes perhatian visual dan kecepatan persepsi lebih rendah saat menjelang siang dibanding subyek yang meminum cukup air. ${ }^{11,12}$ Pada temuan lain menunjukan perbaikan yang bermakna dalam memori, perhatian visual, memori visual, dan pencarian visual setelah penyediaan air tambahan dan dampak negatif dehidrasi pada memori jangka pendek..$^{13,14}$

Hasil penelitian ini menunjukkan ada hubungan antara tingkat kebugaran jasmani dengan daya konsentrasi $(p<0,05)$. Nilai korelasi positif menunjukkan semakin baik tingkat kebugaran jasmani semakin baik juga daya konsentrasinya. Rerata subyek memiliki tingkat kebugaran jasmani kurang bugar $(31,27 \pm 8,00)$. Penelitian ini serupa dengan penelitian pada anak pra-remaja yang menunjukkan adanya hubungan antara kebugaran kardiorespirasi dengan kemampuan kognisi, salah satunya adalah perhatian. Anak pra-remaja dengan status kebugaran yang baik (VO2max atas persentil ke-70) memiliki amplitudo P3 lebih tinggi dibandingkan dengan anak-anak pra-remaja yang kurang bugar (VO2max bawah persentil 30). Hal ini menunjukkan bahwa tingkat kebugaran jantung paru yang rendah berhubungan dengan kurangnya fungsi kognitif untuk memenuhi tuntutan tugas. ${ }^{6}$ Anak dengan kebugaran yang baik memiliki waktu reaksi yang lebih cepat daripada anak-anak yang memiliki kebugaran rendah. Hal ini menunjukkan bahwa kebugaran berhubungan dengan indeks neuroelectricperhatian dan memori kerja, serta kecepatan respon pada anak-anak. ${ }^{15}$

Penelitian lain menemukan hubungan yang bermakna antara kebugaran kardiorespirasi dengan tes digit simbol. ${ }^{16}$ Hubungan antara kebugaran kardiorespirasi dan fungsi kognitifmemiliki beberapa mekanisme. ${ }^{17}$ Salah satu mekanismenya adalah bahwa rendahnya kebugaran kardiorespirasi menyebabkan perubahan morfologi otak termasuk subtansi putih, dan terjadi atrofi otak pada daerah subtansi abu-abu, yang selanjutnya berhubungan dengan gangguan fungsi kognitif. ${ }^{17,18}$ Mekanisme yang lain adalah bahwa kebugaran kardiorespirasi dapat mengubah fungsi kognitif melalui regulasi aliran darah di otak, atau melalui jalur molekuler langsung di luar sistem vaskular, seperti mempengaruhi metabolisme $N$-acetylaspartate di badan sel neuron yang efeknya diidentifikasi pada hubungan antara kebugaran dan tes perhatian. ${ }^{19,20}$

\section{SIMPULAN}

Terdapat hubungan yang bermakna antara status hidrasi dengan daya konsentrasi anak sekolah dasar, dimana semakin dehidrasi semakin rendah daya konsentrasi. Terdapat hubungan yang bermakna antara tingkat kebugaran jasmani dengan daya konsentrasi anak sekolah dasar, dimana semakin baik tingkat kebugaran jasmani semakin baik daya konsentrasi.

\section{UCAPAN TERIMA KASIH}

Terima kasih kami ucapkan kepada Kepala UPTD Pendidikan kecamatan Tembalang, Kepala Sekolah dan guru-guru SDN Rowosari 1, subyek penelitian dan orang tuanya yang telah berpartisipasi pada penelitian ini.

\section{DAFTAR PUSTAKA}

1. Je'quier E, F Constant. Water as an essential nutrient: the physiological basis of hydration. Eur J Clin Nutr. 2010; 64: 115-23.

2. Hall JA. Hydration and cognition in young adults (thesis). Ohio: Ohio University; 2005.

3. Suhr JA, Hall J, Patterson SM, Niinisto RT. The relation of hydration status to cognitive 
performance in healthy older adults. Int $\mathrm{J}$ Psychophysiol. 2004;53: 121-5.

4. Cian C, Barraud PA, Melin B, Raphel C. Effects of fluid ingestion on cognitive function after heat stress or exercise-induced dehydration.Int J Psychophysiol. 2001; 42:243-51.

5. Trinies V, Chard AN, Mateo T, Freeman MC. Effects of water provision and hydration on cognitive function among primary-school pupils in Zambia: a randomized trial. PLoS ONE. 2006: 11(3):1-6.

6. Briawan D, Paramitha R, Kartika A. Kebiasaan konsumsi minuman dan asupan cairan pada anak usia sekolah di perkotaan . Jurnal Gizi dan Pangan. 2011; 6(3): 186-91.

7. Pontifex MB, Raine LB, Johnson CR, Chaddock L, Voss MW, Cohen NJ, et al. Cardiorespiratory fitness and the flexible modulation of cognitive control in preadolescent children. Journal of Cognitive Neuroscience.2011: 23(6):1332-45.

8. Decher NR, Douglas JC, Susan WY,Matthew SG, Michelle LL, Catie LD et al. Hydration status, knowledge, and behavior in youths at summer sports camps. Int J Sports Physiol Perform.2008; 3: 262-78.

9. Jacks DE, Robert T, Justin BM. Prediction of VO2 peak using a sub-maximal bench step test in children. Clinical Kinesiology. 2011; 65(4): 68.

10. Kim CJ, Sang-hyun H, Byung-Sam K, Joon-Pyo C, Yoonki L,Hyun-Jung $\mathrm{K}$, et al. Comparison of various tests designed to assess the recovery of cognitive and psychomotor function after ambulatory anesthesia. Korean J Anesthesiol. 2008;55(3):291-7.

11. Edmonds CJ, Burford D. Should children drink more water? The effects of drinking water on cognition in children. Appetite. 2009: 52:776-9.

12. Bar-David Y, Urkin J, Kozminsky E: The effect of voluntary dehydration on cognitive functions of elementary school children. Acta Paediatr.2009: 94:1667-73.
13. Edmonds CJ, Jeffes B. Does having a drink help you think? 6-7-Year-old children show improvements in cognitive performance from baseline to test after having a drink of water. Appetite. 2009; 53(3):469 72.

14. Fadda R, Rapinett G, Grathwohl D, Parisi M, Fanari $\mathrm{R}$, Cao CM, et al. Effects of drinking supplementary water at school on cognitive performance in children. Appetite. 2012; 59(3):730-7.

15. Hillman CH, Castelli DM, Buck SM. Aerobic fitnessand neurocognitive function in healthy preadolescent children. Med Sci Sports Exerc. 2005; 37(11): 1967-74.

16. Zhu N. Cardiorespiratory fitness in relation to cognitive function, brain MRI measures, and quality of life in middle-aged population (Dissertation). Minnesota: University of Minnesota; 2013.

17. Sen A, Gider P, Cavalieri M, Freudenberger P, Farzi A, Schallert $M$, et al. Association of cardiorespiratory fitness and morphological brain changes in the elderly: results of the austrian stroke prevention study. Neurodegener Dis. 2012;10(14):135-7.

18. Prakash RS, Snook EM, Motl RW, Kramer AF. Aerobic fitness is associated with gray matter volume and white matter integrity in multiple sclerosis. Brain Res. 2010;1341:41-51.

19. Brown AD, McMorris CA, Longman RS, Leigh R, Hill MD, Friedenreich CM, et al. Effects of cardiorespiratory fitness and cerebral blood flow on cognitive outcomes in older women. Neurobiol Aging. 2010;31(12):2047-57.

20. Erickson KI, Weinstein AM, Sutton BP, Prakash RS, Voss MW, Chaddock L, et al. Beyond vascularization: Aerobic fitness is associated with $\mathrm{N}$-acetylaspartate and working memory. Brain Behav.2012;2(1):32-41. 